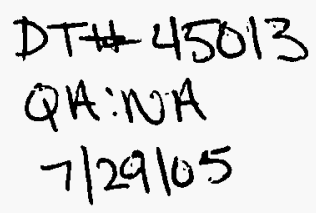

The Proposed Yucca Mountain Repository from a Corrosion Perspective

Joe H. Payer

Department of Materials Science and Engineering

MOL. 20051025.0109

Case Western Reserve University

Cleveland, Ohio 44106-7204, U.S.A.

\begin{abstract}
In this paper, the proposed Yucca Mountain Repository is viewed from a corrosion perspective. A major component of the long-term strategy for safe disposal of nuclear waste at the Yucca Mountain Repository is first to completely isolate the radionuclides in the waste packages for long times and to greatly retard the egress and transport of radionuclides from penetrated packages. Therefore, long-lived waste packages are important. The corrosion resistance of the waste package outer canister is reviewed, and a framework for the analysis of localized corrosion processes is presented. An overview is presented of the Materials Performance targeted thrust of the U.S. Department of Energy/Office of Civilian Radioactive Waste Management's Office of Science and Technology and International. The thrust program strives for increased scientific understanding, enhanced process models and advanced technologies for corrosion control.
\end{abstract}

\title{
INTRODUCTION
}

Corrosion is a primary determinant of waste package performance at the proposed Yucca Mountain Repository and will control the delay time for radionuclide transport from the waste package. The terrain above the proposed repository and a schematic drawing of waste packages in a drift are shown in figure 1 and 2, respectively. Corrosion is the most probable and most likely degradation process that will determine when packages will be penetrated and the shape size and distribution of those penetrations. In this paper, the proposed Yucca Mountain Repository is viewed from a corrosion perspective. While the views expressed here are those of the author, this paper is based on a presentation to the Nuclear Waste Technical Review Board, May 18-19, 2004 [1]. A number of scientists and engineers working on the Yucca Mountain Project contributed to that presentation.

\section{CORROSION PERSPECTIVES}

\section{Corrosion resistance of the waste package outer canister}

A major component of the long-term strategy for safe disposal of nuclear waste at the proposed Yucca Mountain Repository is first to completely isolate the radionuclides in the waste packages for long times and to greatly retard the egress and transport of radionuclides from penetrated packages. Highly corrosion resistant metals are selected for the waste packages and drip shields of the proposed Repository: Alloy 22, a nickel-chromium-molybdenum alloy and titanium, respectively. Both Alloy 22 and titanium have high corrosion resistance in the oxidizing environments of interest for the proposed Repository. This has been recognized by 


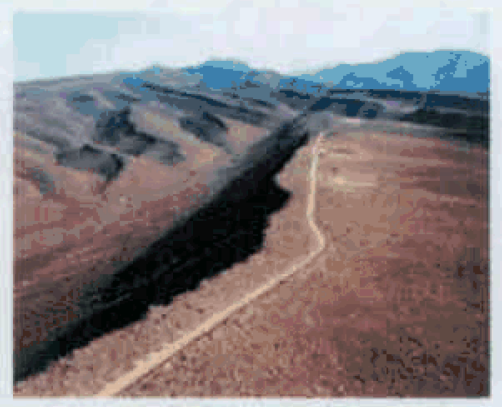

Figure 1 Proposed Yucca Mountain Repository

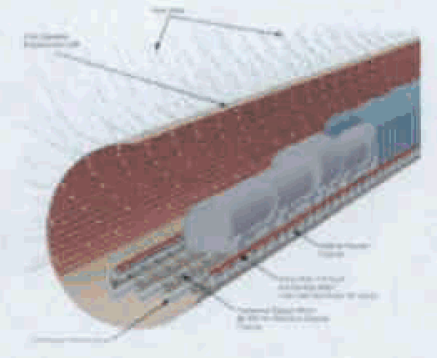

Figure 2 Waste packages in a drift.

European Commission (EC) countries, who have investigated both metals for potential use as waste package materials in salt, clay and granite environments as part of the EC's Fifth Framework Programme [2]

Alloy 22 is a member of a corrosion resistant family of alloys that were developed for highly aggressive, oxidizing acid applications. These alloys and titanium are at the top-of-the-list for corrosion resistance. The passive corrosion rates of Alloy 22 and titanium are measured at 0.1 to $0.01 \mathrm{um} / \mathrm{yr}$ and less. Based on these rates, the penetration of one millimeter of the passive metals would take 16,000 to 160,000 years, and the outer canister of Alloy 22 is on the order of $20 \mathrm{~mm}$ thick. Therefore, passive metals that remain passive can provide extremely long service lives.

\section{A framework for the analysis of localized corrosion processes}

The proposed Repository presents a familiar materials performance application that is regularly encountered in energy, transportation and other industries. The widely accepted approach to dealing with materials performance is to identify the performance requirements, to determine the operating conditions to which materials will be exposed and to select materials of construction that perform well in those conditions. A special feature of the proposed Yucca Mountain Repository is the extremely long time frame of interest, i.e. 10,000's of years and longer. Thus, the time evolution of the environment in contact with waste package surfaces and the time evolution of corrosion damage that may result are of primary interest in the determination of expected performance.

Since no material is immune to all environmental conditions, an approach is to specify a material with sufficient corrosion resistance over the range of expected environments. The objective is to determine the corrosion behavior over a broad range of environments that cover the expected conditions. Thermal-hydrological-chemical models and experiments determine the water chemistry and temperature ranges of interest $[3,4]$. Waters can be grouped into categories of relevance to corrosion behavior, e.g. carbonate waters, sodium-potassium chloride-nitrate waters, and calcium-magnesium chloride-nitrate waters. The chemical divide processes as illustrated in figure 3 determine the evolution of water chemistries into the categories of waters shown in figure 4.

Corrosion resistance is determined by long-term exposure of metal specimens and widely accepted electrochemical tests. For example, forward-reverse polarization tests on specimens under fully immersed conditions with severe crevice formers determine the localized corrosion 


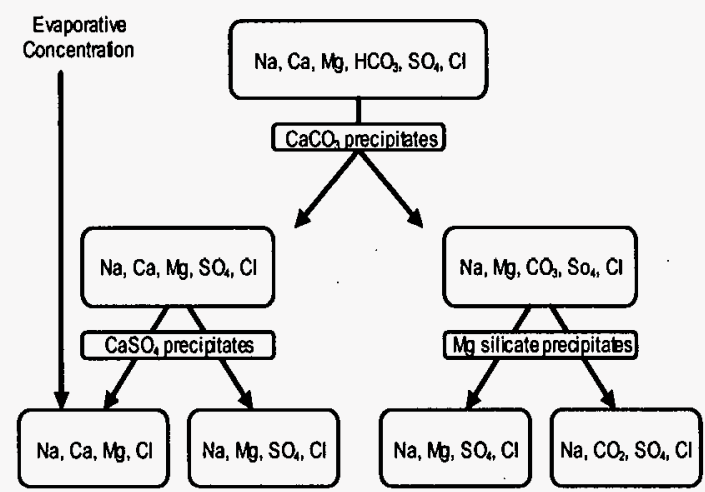

Figure 3. Chemical divide processes.

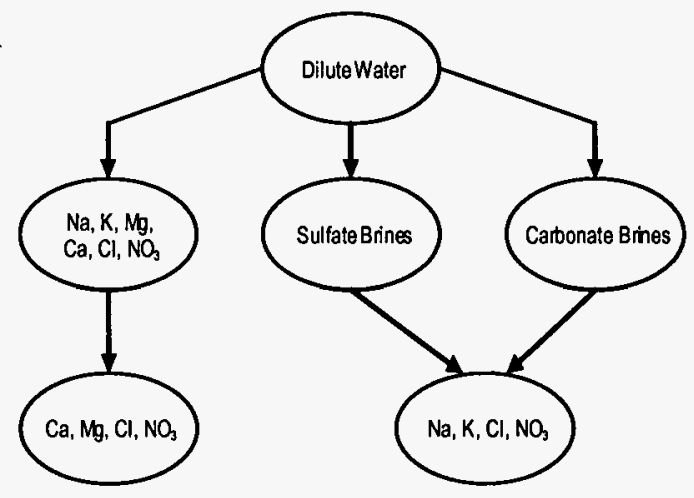

Figure 4. Categories of aqueous solutions.

behavior as a function of solution composition, acidity $(\mathrm{pH})$ and temperature. A number of experimental, analytical and computational methods complement and support these studies.

\section{Corrosion Conditions at Key Time Periods in Repository}

From a corrosion perspective, five key time periods are defined for any waste package. The times for these periods vary from package to package depending on thermal load and heat transfer in the drift and to the surrounding rock. As explained below, Period IV is a particularly important period for corrosion analysis. Data for Period IV are presented in Table I for scenarios with mid, hot and cool waste packages. Figure 5 shows the time-temperature-relative humidity trajectories for the mid waste package.

Period I is prior to closure, and the drifts are ventilated. Corrosion is not of particular concern during this period because the waste packages are relatively cool, and relative humidity is low. A thermal barrier prevents water from dripping or seeping into the drift and falling upon the hot waste package surfaces as long as the drift wall is above the boiling point for waters. For the scenarios described here, the local boiling point for water at Yucca Mountain elevation is used, i.e. $96 \mathrm{C}$. The thermal barrier develops during the heat up period after closure at the start of Period II and continues through Period III. While the thermal barrier is present, corrosion is of less concern because water can not drip from the drift onto hot metal surfaces. Period V starts when the waste package surface has cooled below the critical temperature for corrosion of Alloy 22 , i.e. taken as $90 \mathrm{C}$ for these scenarios.

The start of Period IV is defined as the time when the thermal barrier has dissipated and drips and seepage of water can come from the rock into the drift. For the three scenarios described here, Period IV extends for 625 years (years 750 to 1375) for the mid waste package, 1100 years (years 1900 to 3000 ) for the hot waste package, and 63 years (years 112 to 175) for the cool waste package. While the time scale remains special, in this perspective, the corrosion analysis becomes more conventional. Metal structures are being designed for useful lives of 50 100 years, and there are a number of metal artifacts that remain from 1000's of years ago. 


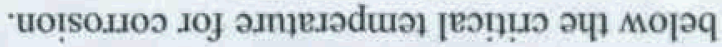

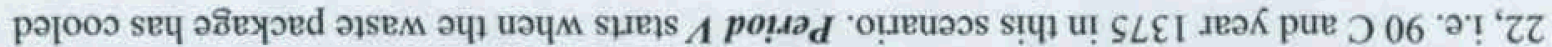

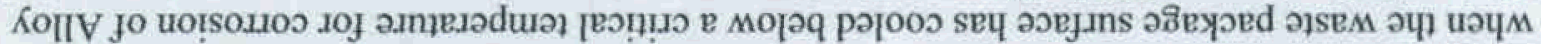

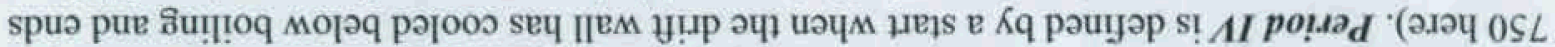

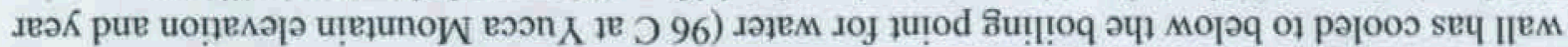

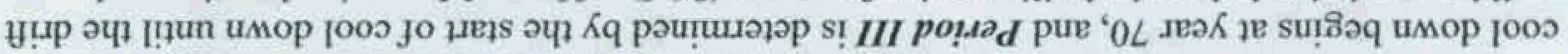

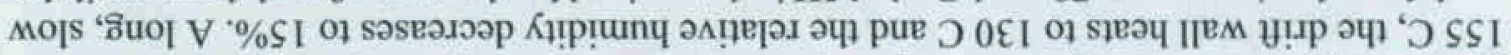

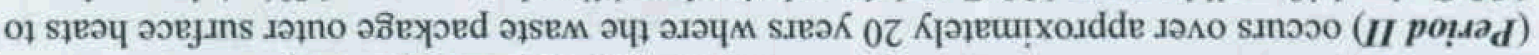

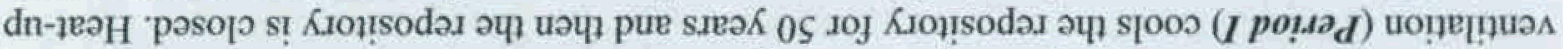

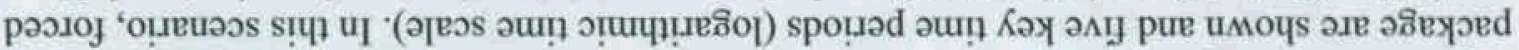

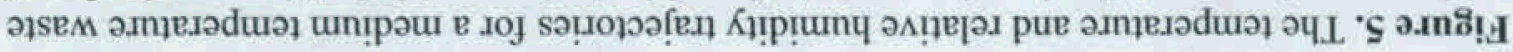

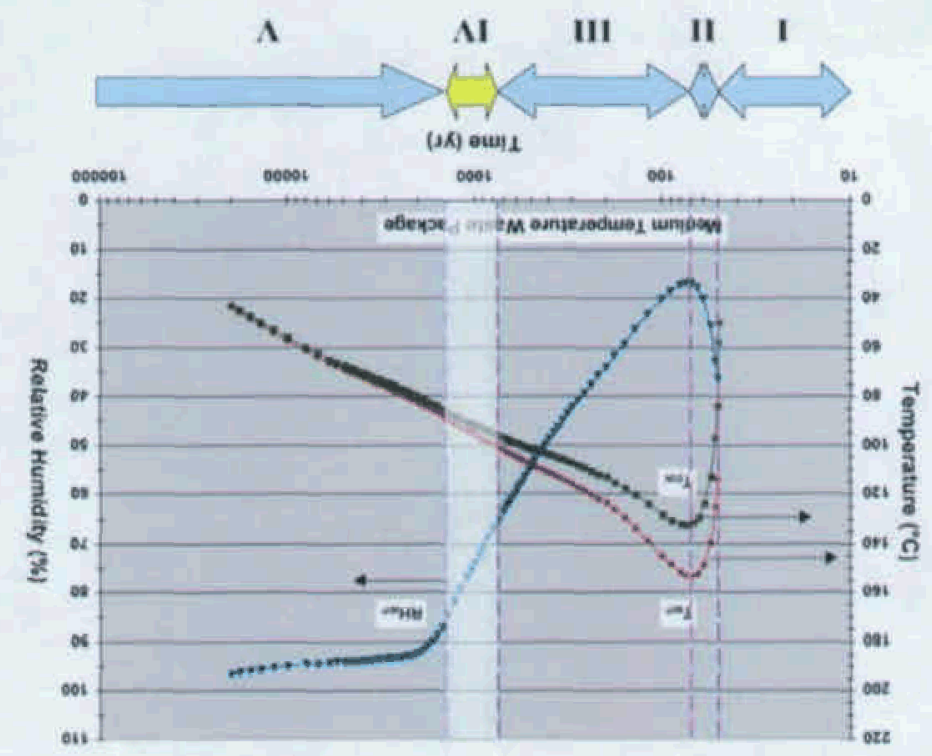

\begin{tabular}{|c|c|c|c|c|}
\hline SLL & $z L$ & $20 l$ & $z \mathrm{tl}$ & dM 1005 \\
\hline oooe & 99 & 66 & $006 t$ & $\mathrm{dM} 20 \mathrm{H}$ \\
\hline sLEL & s9 & Lot & osL & dM PIW \\
\hline دеอ人 & 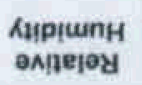 & 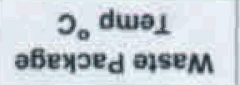 & sea $\lambda$ & \\
\hline 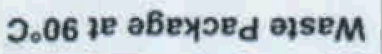 & \multicolumn{3}{|c|}{ ว.96 ॥ем нนа } & \\
\hline
\end{tabular}

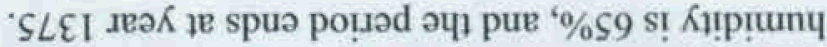

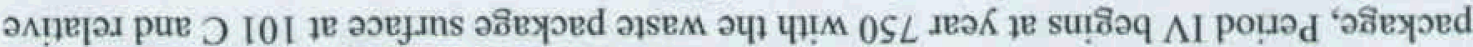

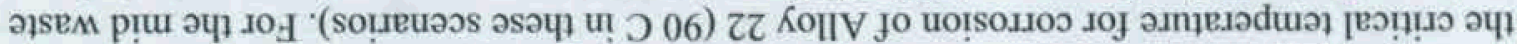

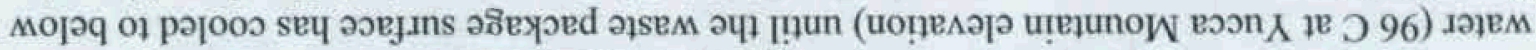

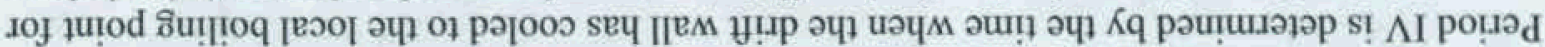

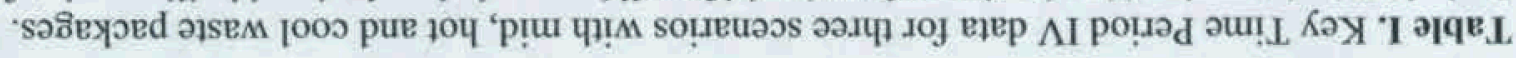


Period IV time periods are when waters from the rock can fall onto hot metal surfaces. Once the packages have cooled below a critical temperature for corrosion, no further damage by localized corrosion will occur. While a drip shield is designated as an integral part of the engineered barrier system to prevent any water from directly falling from the rock onto the waste package surface, it is prudent to analyze the corrosion behavior of Alloy 22 under conditions from drips and seepage of water.

\section{Corrosion Analysis during Period IV-Cool Down/Dripping and Seepage Possible}

An approach to the analysis during Period IV is illustrated which combines data for the time-temperature-relative humidity trajectories for waste packages along with information on the water chemistry behavior for binary solutions of $\mathrm{NaCl}$ and $\mathrm{KNO}_{3}$. Other salts and salt assemblages can be similarly treated. Figure 6 shows scenarios for three waste packages, and tracks the time evolution of the aqueous environment in contact with waste package surfaces. This information is combined with knowledge of the corrosion behavior of Alloy 22 to determine the time evolution of corrosion damage. For example, laboratory experiments find that localized corrosion of Alloy 22 is inhibited in solutions that have a sufficient nitrate to chloride ratio, e.g. $\mathrm{NO}_{3}: \mathrm{Cl}$ greater than 0.2 at $80 \mathrm{C}$. For the illustration in Figure 6, the $\mathrm{NO}_{3}: \mathrm{Cl}$ ratio of 0.5 is denoted.

The mid range waste package described in Figure 5, begins the cool down period with a temperature of approximately $160 \mathrm{C}$ and relative humidity of $15 \%$ and this point is plotted on Figure 6. With time, the waste package surface cools and the relative humidity in the drift increases. This traces a time trajectory that rises from this starting point toward the upper left in the diagram. For this scenario, the thermal barrier (drift wall above boiling) persists until year 750 when the waste package surface temperature is $101 \mathrm{C}$ and the relative humidity in the drift is $65 \%$. For these conditions, the $\mathrm{NO}_{3}: \mathrm{Cl}$ ratio is greater than 0.5 and no localized corrosion occurs. From year 750, the trajectory continues toward the upper left and moves through the water chemistry zones that are noted. The trajectory terminates where the waste package surface is approximately $50 \mathrm{C}$ and relative humidity in the drift is $95 \%$. From Figure 5, it is seen that this is at year 20,000, and the calculations can be continued to longer times if desired.

When the waste package surface is dry, there is no corrosion, and there is a critical temperature below which localized corrosion of Alloy 22 will not occur in waters of a specified composition. For this scenario, a critical temperature of $90 \mathrm{C}$ is specified, and the waste package surface cools below this temperature in year 1375. The time period over which corrosion damage can occur is constrained by these two limits, i.e. years 750-1375 for this scenario. Furthermore, the water chemistry of mixed salt solutions is the determinant of temperature-relative humidity conditions within this range. Based on corrosion performance data for Alloy 22, the conditions that will and will not support localized corrosion are delineated. There are large time periods when localized corrosion can not be supported, and no corrosion damage will occur. The analysis can then focus on those time periods when localized corrosion could occur.

\section{Decision-Tree Analysis}

An outcome from the analysis described above is that the important time periods when localized corrosion could occur on waste packages are restricted to finite time periods. For the 

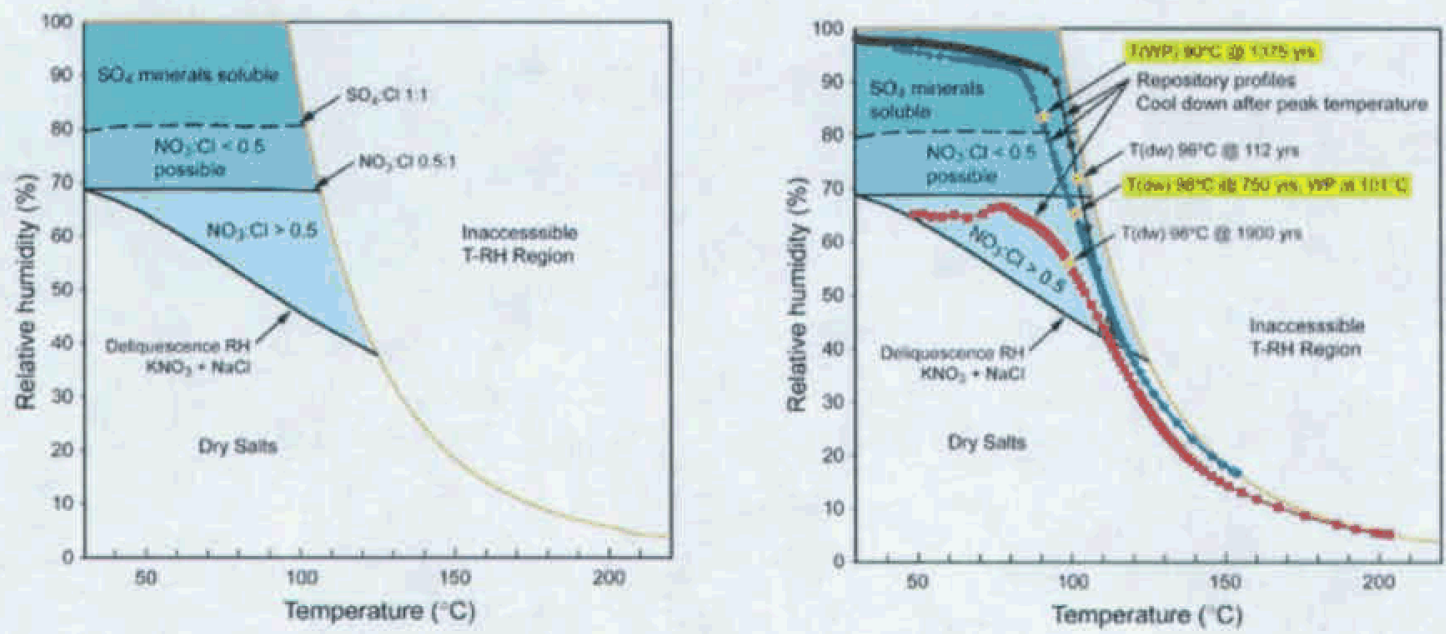

Figure 6. The behavior of a binary mixture of $\mathrm{NaCl}$ and $\mathrm{KNO}_{3}$ is shown on the left as a function of relative humidity and temperature. The inaccessible region is determined by atmospheric pressure in the drifts. All binary salt mixtures below the deliquescence relative humidity line are dry (and no corrosion will occur). Pure $\mathrm{NaCl}$ deliquesces at approximately $115 \mathrm{C}$ and $\mathrm{RH} 40 \%$. Where aqueous solutions are possible (upper left quadrant), there are constraints on the chemical composition. Below approximately $70 \% \mathrm{RH}$, the nitrate to chloride ratio must be greater than 0.5:1 (and localized corrosion is inhibited). The temperature- $\mathrm{RH}$ trajectories of the mid, hot and cool waste packages described earlier have been plotted on the diagram on the right, and some key times for Period IV are indicated. The significance of this illustration is to demonstrate that the time-temperature-relative humidity behavior is coupled to the water chemistries that can exist on hot metal surfaces, and the trajectories of aqueous environments can be determined.

time periods where localized corrosion can be supported based upon the temperature and possible water chemistries, a decision-tree analysis can be applied to determine the evolution of corrosion damage over time. A decision-tree approach to localized corrosion for the proposed Yucca Mountain repository has been described previously $[1,5]$. While the individual steps vary, the overall approach and structure of the decision trees are comparable.

A decision-tree for localized corrosion [1] is presented in figure 7. Questions considered are:

- Are environments and crevices present to induce localized corrosion? Consider conditions in moist layers of particulate and deposits.

- If localized corrosion initiates, will it persist? Consider corrosion stifling and arrest as the process proceeds.

- What amount of metal penetration occurs?

- What is the size and distribution of corrosion sites?

Based on these considerations, one may determine the evolution of corrosion damage over time. In this analysis, localized corrosion can only proceed when several barriers are overcome, i.e. thermal barrier, capillary barrier and drip shield. Then, water must drip or seep onto the hot, waste package surface and the aqueous environment must be sufficiently corrosive to support crevice corrosion. When these prerequisites are met, then the considerations in the final column to the right are analyzed to determine the evolution of corrosion damage. 


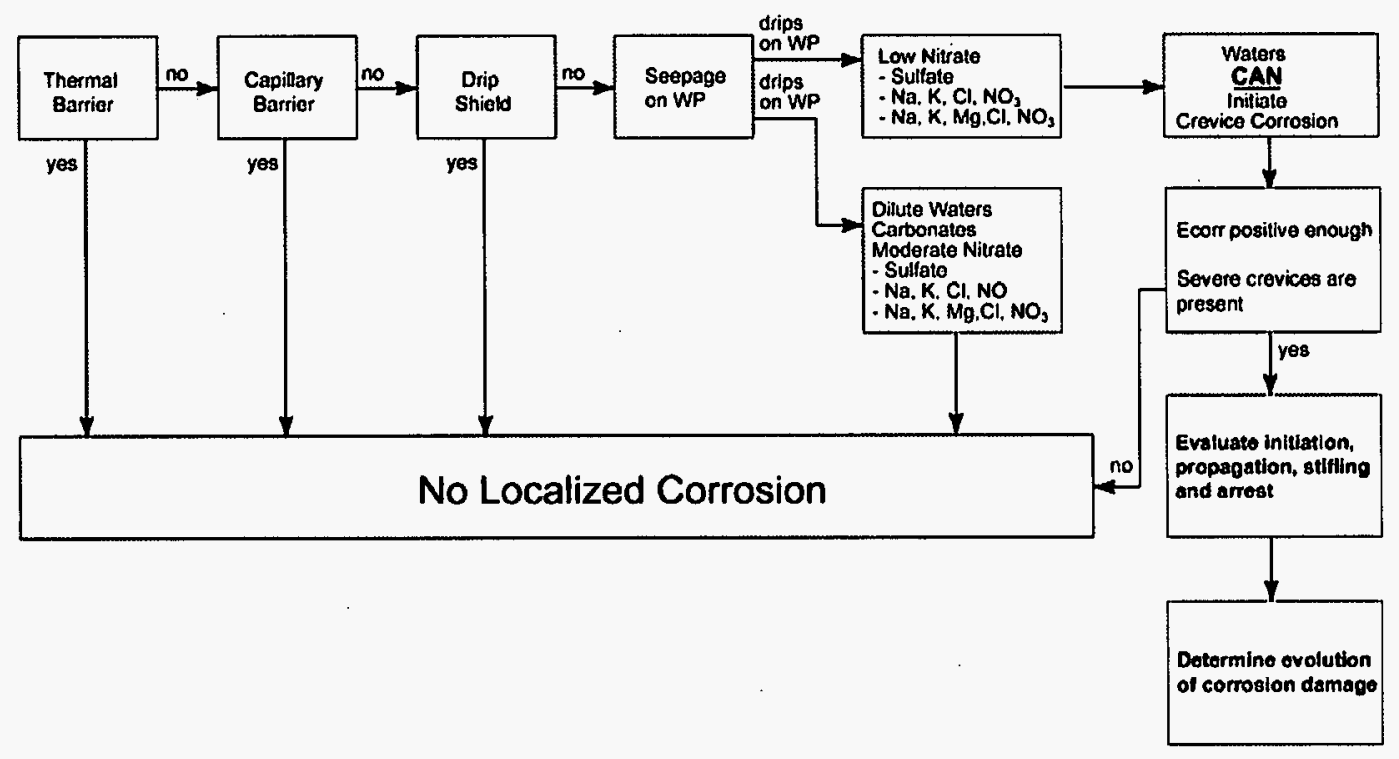

Figure 7. A decision-tree diagram for localized corrosion.

\section{SCIENCE AND TECHNOLOGY: MATERIALS PERFORMANCE THRUST}

The goal of the Materials Performance Targeted Thrust is to further enhance the understanding of the role of engineered barriers in waste isolation. In addition, the Thrust will explore technical enhancements and seek to offer improvements in materials costs and reliability. A team of leading scientists/engineers from major universities and national laboratories is working together to meet the program objectives. This group brings expertise and specialized facilities in important disciplines including corrosion science, materials science, electrochemistry, physical chemistry and geochemistry. The team is organized to address important topics:

- Long-term behavior of protective, passive films

- Composition and properties of moisture in contact with metal surfaces

- Rate of penetration and extent of corrosion damage over extremely long times. There are three multi-investigator, coordinated projects currently underway.

Corrosion of metal surfaces covered with particulate and deposits: The waste packages are supported in air, and they will never be fully immersed in water, rather the metal surfaces may be covered with dust, particulate and moisture from the surrounding rock and humidity. This technical thrust examines corrosion in thin moisture films and layers of particulate and deposits.

Evolution of corrosion damage by localized corrosion: Localized corrosion processes and particularly crevice corrosion are high priorities. This technical thrust examines the rate of penetration and extent of corrosion damage by localized corrosion over extremely long times.

Evolution of environment on metal surfaces: The corrosion performance of a metal is determined by the inherent corrosion resistance of the metal and the corrosivity of the environment. The amount, distribution and chemical composition of the moisture on waste packages are important. 


\section{SUMMARY}

The proposed Yucca Mountain Repository was viewed from a corrosion perspective. The corrosion resistance of the waste package outer canister was reviewed, and a framework for the analysis of localized corrosion processes was presented. From a corrosion perspective, five key time periods were defined for any waste package. Period IV was identified as a particularly important period for corrosion analysis, and it was defined by a start when the drift wall has cooled below boiling and an end when the waste package surface has cooled below a critical temperature for corrosion of Alloy 22. During this time period water can drip or seep from the rock onto hot metal surfaces in the drift. An approach to the analysis during Period IV was illustrated which combines data for the time-temperature-relative humidity trajectories for waste packages along with information on the water chemistry behavior for binary solutions of $\mathrm{NaCl}$ and $\mathrm{KNO}_{3}$. An outcome from the analysis was that the important time periods when localized corrosion could occur on waste packages are restricted to finite time periods. Further, the compositions of waters on metal surfaces during these periods are constrained within compositional zones. A decision-tree approach to localized corrosion for the proposed Yucca Mountain repository was described. An overview was presented of the Materials Performance targeted thrust of the U.S. Department of Energy/Office of Civilian Radioactive Waste Management's Office of Science and Technology and International.

\section{ACKNOWLEDGMENTS}

Support by the Office of Science and Technology International of the U.S. Department of Energy, Office of Civilian Radioactive Waste Management is gratefully acknowledged. The following provided useful input: Susan Carroll, Greg Gdowski, Gabriel Ilevbare, Tiangan Lian, Chris Orme, Raul Rebak, Tammy Summers, Tom Wolery of Lawrence Livermore National Laboratory; Gerald Gordon, Pasu Pasupathi of Bechtel SAIC Company; Mark Peters of Argonne National Laboratory; Bo Bodvarsson, Carl Steefel of Lawrence Berkeley National Laboratory.

\section{REFERENCES}

1. J. Payer, “Corrosion Resistance of Alloy 22”, U.S. Nuclear Waste Technical Review Board, May 18-19, 2004, Washington, DC, www.nwtrb.gov

2. E. Smailos, M.A. Cunado, I. Azkarate, B. Kursten, G. Marx, Long-Term Performance of. Candidate Materials for HLW/Spent Fuel Disposal Containers, Wissenschaftliche Berichte FZKA 6809, Forshungszentrum Karlsruhe GmbH, 2003, Kahrlsruhe, Germany. http://bibliothek.fzk.de/zb/berichte/FZKA6809.pdf

3. C. Steefel, "The In-Drift Chemical Environment during the Below-Boiling Period", U.S. Nuclear Waste Technical Review Board, May 18-19, 2004, Washington, DC, www.nwtrb.gov

4. G. Bodvarsson, "Thermal Hydrologic Environment and Thermal Seepage", U.S. Nuclear Waste Technical Review Board, May 18-19, 2004, Washington, DC, www.nwtrb.gov

5. J. Kessler, D. Langmuir, F. King, M. Apted, “Analysis of NWTRB's Scenario Regarding Localized Corrosion by Formation of High-Temperature Deliquescent Brines", U.S. Nuclear Waste Technical Review Board, May 18-19, 2004, Washington, DC, www.nwtrb.gov 